\title{
The impact of naturally stored energy reserve of the body in different proportions on type 2 Diabetes mellitus in Puducherry.
}

\author{
Dr. M. Priyatharshini ${ }^{1}$,Dr .P. Muraliswaran ${ }^{2}$,Dr. P. Kanagavalli ${ }^{3}$,Dr. G. Radhika ${ }^{4}$ \\ ${ }^{I}$ (Department Of Biochemistry, Sri Lakshmi Narayanaa Institute Of Medical Sciences, Puducherry, India). \\ ${ }^{2,3,4}$ (Department Of Biochemistry, Sri Venkateshwaraa Medical College Hospital \& Research Centre, \\ Ariyur,Puducherry, India.
}

\begin{abstract}
:
Background: The increase in type 2 diabetes is directly related to the environmental risk factors, especially overweight and obesity, which superimposed on genetic predisposition results in progressive beta cell failure and insulin resistance. The relative risk for type 2 Diabetes increases as the Body mass index increases.

Objective: 1. To assess the effect of various grades of obesity on type 2 Diabetes mellitus. 2. To correlate the effect of dyslipidemia as a consequence of obesity on type 2 DM.

Materials and Methods: About 200 subjects were included in the study. The subjects were divided into 2 groups: Group 1 - 100 obese individuals (Obese normal + Obese Diabetic) and Group 2 - 100 non obese individuals ( Non obese normal + Non obese Diabetic). The body mass index was correlated with blood sugar and lipid profile. Statistical analysis were done using students unpaired t test.

Results: The lipid profile increased significantly with increase in BMI. The lipid profile was significantly higher (p< $0.0001)$ in obese diabetic people when compared to non obese diabetics. The relative risk of diabetes increases with increasing BMI in the obese normal individuals.

Conclusion: Obesity is an exaggeration of normal energy reserve of the body. It is the major contributor to the metabolic dysfunction involving lipid and glucose as well as complicating the clinical symptoms in subjects suffering from type 2 diabetes.
\end{abstract}

Keywords: obesity,diabetes, lipid profile and body mass index.

\section{Introduction}

Diabetes mellitus, is an emerging pandemic. It is one of the major health problems affecting people throughout the world, associated with potentially life threatening co - morbidities and economic cost[1]. In India, the prevalence of diabetes has increased so rapidly. It is mainly attributed to the rapid life style changes[2]. The increase in type 2 diabetes is directly related to the environmental risk factors, especially overweight and obesity, which superimposed on genetic predisposition results in progressive beta cell failure and insulin resistance [3].

Obesity is a chronic health problem and is now considered as a global epidemic, affecting people worldwide irrespective of the age and sex. About $30-60 \%$ of the urban Indians are either overweight or obese[4]. This rising prevalence has direct correlation with obesity related co morbidities like hypertension, type 2 diabetes, dyslipidemia, metabolic syndrome and cardiovascular diseases[5]. The major cause of obesity is overeating accompanied by a sedentary life style. This combination only results in the imbalance between intake and expenditure of calories in the body [6].

In order to overcome with this problem of rising prevalence of obesity in India, the Health Ministry has released the guidelines for the BMI cut off, jointly with the ICMR, Diabetes Federation of India and other health organization. Accordingly, the WHO recommended cut off of BMI: $18.5-24.9 \mathrm{~kg} / \mathrm{m} 2$ (normal), $25-29.9 \mathrm{~kg} / \mathrm{m} 2$ (overweight), > $30 \mathrm{~kg} / \mathrm{m} 2$ (obese) was reformed. Hence, any individuals with a BMI of $23 \mathrm{~kg} / \mathrm{m} 2$ will be considered overweight and below that as normal. Those individuals with BMI $>25 \mathrm{~kg} / \mathrm{m} 2$ will be clinically termed as obese[7].

The relative risk for type $2 \mathrm{DM}$ increases as the BMI increases more than 23 [8]. This association was to be stronger in the younger age group of the Asia Pacific region [9]. Many researchers have claimed that this relationship is different in different types of obesity and type 2 DM. Hence the present study was designed to correlate the various grades of obesity with blood sugar and to find the relative risk of diabetes. It was also aimed to analyze whether the lipid abnormalities were the result of obesity that influenced diabetes or resulted from an unbalanced metabolic state of diabetes.

\section{II. materials and methodology:}

This was a hospital based cross- sectional study and was conducted in and around Sri Venkateshwara Medical College Hospital and Research Centre, Puducherry. About 200 subjects were included in the study. An informed consent was obtained from the subjects. Institutional Ethical Committee clearance was obtained before the 
commencement of the study. The subjects were divided into 2 groups: Group $1-100$ obese individuals and Group $2-$ 100 non obese individuals. Further the two groups were subdivided in Subgroup 1 and 2 with individuals having normal blood sugar and individuals having blood sugar in the diabetic range, respectively. The diabetic individuals were selected based on the diagnostic criteria of American Diabetic Association [10].

The person's age, sex, height, weight and blood pressure were recorded. A fasting blood sugar and a lipid profile were measured. Body mass index was calculated (weight in $\mathrm{Kg} / \mathrm{height}$ in $\mathrm{m}^{2}$ ) and was used as criteria for diagnosis of overweight and obesity. Those with BMI between $18.5-22.9 \mathrm{~kg} / \mathrm{m} 2$ were considered normal, $23-24.9 \mathrm{~kg} / \mathrm{m} 2$ as overweight and $>25 \mathrm{~kg} / \mathrm{m} 2$ as obese. The individuals were matched for the age and sex and all the individuals belonged to the age group, $18-60$ yrs.

Exclusion criteria:

- Pregnant ladies,Patients who are critically ill and Type I DM.

\section{Biochemical analysis:}

i)Estimation of fasting and post prandial Blood sugar (GOD-POD enzymatic method)

ii) Estimation of fasting Lipid profile: (enzymatic method)

a. Total cholesterol b.Triglyceride c.HDL cholesterol d.VLDL cholesterol* e. LDL cholesterol*

* - Freidwalds equation.

The Friedewald formula (FF) is an estimation of LDL-c level that uses the following levels of total cholesterol (TC), triglycerides (TG), and high-density lipoprotein cholesterol (HDL-c): LDL-c (mg/dL) $=\mathrm{TC}(\mathrm{mg} / \mathrm{dL})-\mathrm{HDL}-\mathrm{c}$ $(\mathrm{mg} / \mathrm{dL})-\mathrm{TG}(\mathrm{mg} / \mathrm{dL}) / 5$. To be applied in the FF, the measurements of TC, HDL-c, and TG must be in mg/dL; The FF became the standard method for LDL-c assessment because it is economical and simpler than direct assays, the most accurate LDL-c measurement methods [11]. The results were reported as mean $\pm \mathrm{SD}$. The blood sugar level were correlated with BMI using students ' $\mathrm{t}$ ' test and a ' $\mathrm{p}$ ' value $<0.05$ was considered significant. Odds ratio was used to calculate the relative risk.

\section{Results}

Table 1: Anthropometric parameters, fasting blood sugar, Lipid profile

\begin{tabular}{|l|l|l|}
\hline \multirow{2}{*}{ Age } & Obese individuals n $=\mathbf{1 0 0}$ & Non obese individuals n= 100 \\
\hline \multirow{2}{*}{ Bex } & 40.239 .93 & $39.16 \quad 12.04$ \\
\hline & $\mathrm{M}=50$ & $\mathrm{M}=45$ \\
\cline { 2 - 3 } & $\mathrm{F}=50$ & $\mathrm{~F}=55$ \\
\hline Blood sugar & $28.2 \pm 2.9$ & $22.8 \pm 1.55$ \\
\hline Total cholesterol & $143.03 \pm 81.7$ & $134.48 \pm 80.1$ \\
\hline Triglyceride & $171 \pm 47.4$ & $168.9 \pm 44.9$ \\
\hline HDL & $128.07 \pm 86.2$ & $110.24 \pm 58.04$ \\
\hline LDL & $41.88 \pm 7.86$ & $45.54 \pm 7.72$ \\
\hline VLDL & $108.1 \pm 41.07$ & $98.02 \pm 41.79$ \\
\hline
\end{tabular}

The baseline characteristics of the study group were similar

Table 2: The blood sugar and lipid profile pattern in various sub groups.

\begin{tabular}{|l|l|l|l|l|}
\hline \multicolumn{3}{|l|}{ Obese individuals } & \multicolumn{2}{l|}{ Non obese individuals } \\
\hline & Normal $(\mathrm{n}=49)^{\wedge}$ & Diabetic $(\mathrm{n}=51) \#$ & Normal $(\mathrm{n}=55) \$$ & Diabetic $(\mathrm{n}=45)^{*}$ \\
\hline Blood sugar & $84.41 \pm 13.19$ & $205.82 \pm 81.03$ & $81.62 \pm 13.74$ & $176.64 \pm 58.45$ \\
\hline Cholesterol & $172.37 \pm 38.25$ & $176.55 \pm 55.12$ & $168.18 \pm 39.28$ & $169.93 \pm 51.39$ \\
\hline Triglyceride & $114.20 \pm 59.83$ & $141.39 \pm 104.52$ & $98.73 \pm 45.95$ & $124.31 \pm 67.97$ \\
\hline HDL & $42.6 \pm 6.9$ & $41.11 \pm 8.6$ & $47.61 \pm 6.57$ & $43 \pm 8.4$ \\
\hline LDL & $106.85 \pm 33.1$ & $109.3 \pm 47.7$ & $86.52 \pm 30.89$ & $112.07 \pm 48.12$ \\
\hline VLDL & $22.84 \pm 11.9$ & $28.27 \pm 20.9$ & $21.12 \pm 9.3$ & $26.41 \pm 13.04$ \\
\hline
\end{tabular}

$\$$ vs $*$, p value $<0.05$ (significant)

$\$$ vs \#, p value $<0.0001$ (highly significant)

$\$$ vs $\wedge$, blood sugar, $\mathrm{p}$ value 0.2 (not significant)

lipid profile, $\mathrm{p}$ value $<0.01$ (very significant) 
Table 3: Grades of BMI with Blood sugar and Lipid profile

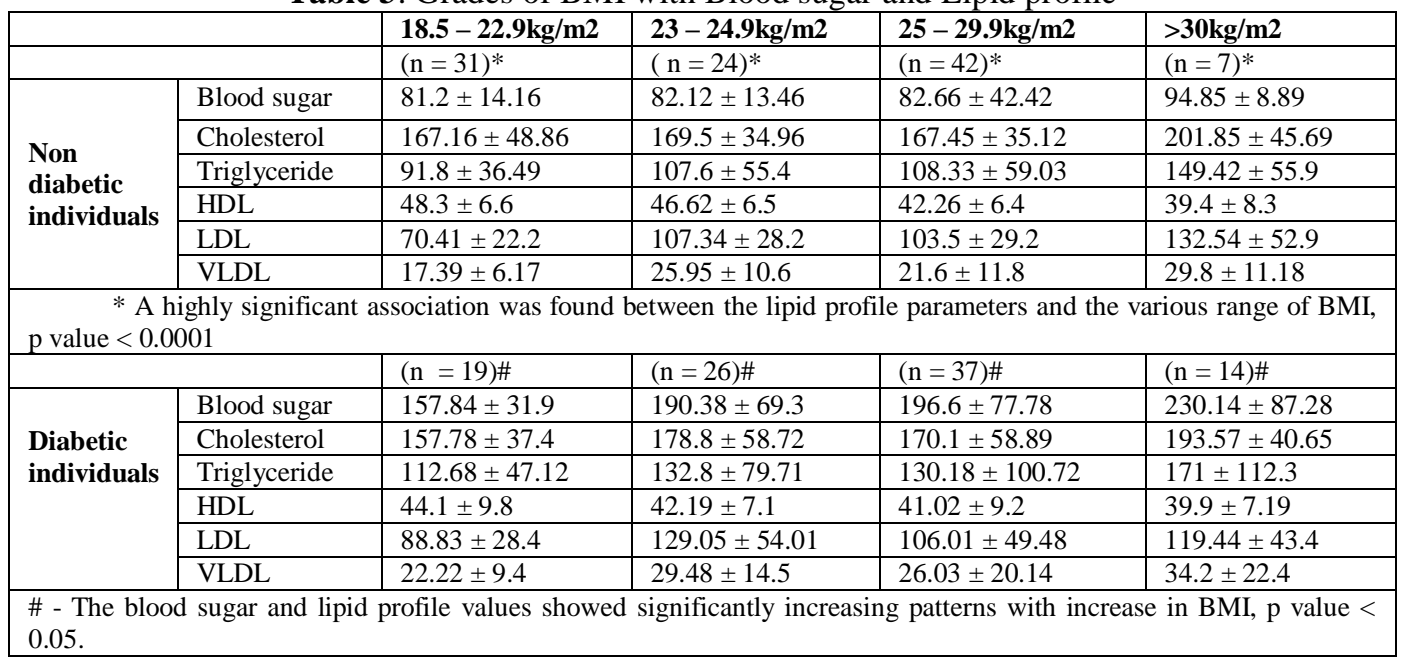

Table 4: Pattern of dyslipidemias in Diabetic and non diabetic individuals

\begin{tabular}{|c|c|c|c|c|c|}
\hline \multirow{5}{*}{$\begin{array}{l}\text { Diabetic } \\
\text { individuals }\end{array}$} & \multirow[t]{2}{*}{ Pattern of dyslipidemias } & \multicolumn{2}{|c|}{$\begin{array}{l}\text { Obese individuals } \\
(\%)\end{array}$} & \multicolumn{2}{|c|}{$\begin{array}{l}\text { Non obese individuals } \\
(\%)\end{array}$} \\
\hline & & Male & Female & Male & Female \\
\hline & $\begin{array}{l}\text { Mixed dyslipidemia }\{\text { TGL } \geq \\
150 \mathrm{mg} / \mathrm{dl}, \mathrm{LDL} \geq 100 \mathrm{mg} / \mathrm{dl}, \mathrm{HDL}< \\
40 \mathrm{mg} / \mathrm{dl} \quad \text { (males), < } 50 \mathrm{mg} / \mathrm{dl} \\
\begin{array}{l}\text { (female) }\}\end{array}\end{array}$ & 30.4 & 21.4 & 22.2 & 29.6 \\
\hline & $\begin{array}{l}2 \text { parameters combined: } \\
\text { a. }(\mathrm{LDL} \geq 100, \mathrm{TG} \geq 150 \& \mathrm{HDL}>40 / 50) \\
\text { b. }(\mathrm{LDL}<100, \mathrm{TG} \geq 150 \& \mathrm{HDL}<40 / 50) \\
\text { c. } \mathrm{LDL} \geq 100, \mathrm{TG}<150 \& \mathrm{HDL}<40 / 50)\end{array}$ & $\begin{array}{l}34.7 \\
39.1 \\
56.5\end{array}$ & $\begin{array}{l}21.4 \\
28.5 \\
32.1\end{array}$ & $\begin{array}{l}27.7 \\
22.2 \\
50\end{array}$ & $\begin{array}{l}29.6 \\
33.3 \\
48.1\end{array}$ \\
\hline & $\begin{array}{l}\text { Isolated single parameter: } \\
\text { a.LDL } \geq 100, T G<150 \& H D L>40 / 50 \text { ) } \\
\text { b. } L D L<100, T G \geq 150 \& H D L>40 / 50 \text { ) } \\
\text { c. } L D L<100, T G<150 \& H D L<40 / 50 \text { ) }\end{array}$ & $\begin{array}{l}65.2 \\
43.4 \\
78.2\end{array}$ & $\begin{array}{l}42.8 \\
28.5 \\
57.1\end{array}$ & $\begin{array}{l}72.2 \\
33.3 \\
66.6\end{array}$ & $\begin{array}{l}55.5 \\
37.03 \\
66.6\end{array}$ \\
\hline
\end{tabular}

\begin{tabular}{|c|c|c|c|c|c|}
\hline \multirow{5}{*}{$\begin{array}{l}\text { Non diabetic } \\
\text { individuals }\end{array}$} & \multirow[t]{2}{*}{ Pattern of dyslipidemias } & \multicolumn{2}{|c|}{$\begin{array}{l}\text { Obese individuals } \\
(\%)\end{array}$} & \multicolumn{2}{|c|}{$\begin{array}{l}\text { Non obese individuals } \\
(\%)\end{array}$} \\
\hline & & Male & Female & Male & Female \\
\hline & $\begin{array}{l}\text { Mixed dyslipidemia }\{\text { TGL } \geq \\
150 \mathrm{mg} / \mathrm{dl}, \mathrm{LDL} \geq 100 \mathrm{mg} / \mathrm{dl}, \mathrm{HDL}< \\
40 \mathrm{mg} / \mathrm{dl} \quad \text { (males), }<50 \mathrm{mg} / \mathrm{dl} \\
\text { (female) }\}\end{array}$ & 3.7 & 27.2 & 0 & 14.2 \\
\hline & $\begin{array}{l}2 \text { parameters combined: } \\
\text { a. }(\mathrm{LDL} \geq 100, \mathrm{TG} \geq 150 \& \mathrm{HDL}>40 / 50) \\
\text { b. }(\mathrm{LDL}<100, \mathrm{TG} \geq 150 \& \mathrm{HDL}<40 / 50) \\
\text { c. } \mathrm{LDL} \geq 100, \mathrm{TG}<150 \& \mathrm{HDL}<40 / 50)\end{array}$ & $\begin{array}{l}11.1 \\
7.4 \\
22.2 \\
\end{array}$ & $\begin{array}{l}27.2 \\
27.2 \\
54.5\end{array}$ & $\begin{array}{l}7.4 \\
0 \\
11.1 \\
\end{array}$ & $\begin{array}{l}14.2 \\
17.8 \\
25\end{array}$ \\
\hline & $\begin{array}{l}\text { Isolated single parameter: } \\
\text { a.LDL } \geq 100, \mathrm{TG}<150, \mathrm{HDL}>40 / 50 \text { ) } \\
\text { b.LDL }<100, \mathrm{TG} \geq 150 \& \mathrm{HDL}>40 / 50 \text { ) } \\
\text { c. } \mathrm{LDL}<100, \mathrm{TG}<150 \& \mathrm{HDL}<40 / 50 \text { ) }\end{array}$ & $\begin{array}{l}33.3 \\
22.2 \\
51.8\end{array}$ & $\begin{array}{l}81.8 \\
27.2 \\
63.6\end{array}$ & $\begin{array}{l}37 \\
14.8 \\
22.2\end{array}$ & $\begin{array}{l}28.5 \\
21.4 \\
46.4\end{array}$ \\
\hline
\end{tabular}

O With normal weight individuals as a reference, individuals in obesity had an adjusted odds ratio of 1.27 (95\% CI 0.70 to 2.31 ) for diabetes.

- The most common pattern of dyslipidemia among diabetics was combined dyslipidemia with high LDL cholesterol and low HDL cholesterol.

O The most prevalent lipid abnormality in our study was low HDL followed by high LDL.

\section{Discussion}

The obesity epidemic is of considerable importance since it runs parallel to the type $2 \mathrm{DM}$. It is important to single out obesity as it plays an important role in the development of abnormalities related to glucose and lipid metabolism [12].Cardiovascular diseases are the major causes of morbidity and mortality, especially in patients with type 2 diabetes mellitus. The risk increases when associated with obesity[13]. Many epidemiological studies have indicated that Indians are highly susceptible to diabetes and cardiovascular risk even with a modest overweight and 
obesity. It seems that the margin of safety between normal and abnormal values of BMI is low in Indians. Hence, BMI becomes an important factor in determining the risk of diabetes, which is clearly evident in the present study [14].

According to an international obesity task force, it was estimated that 1.7 billion people were exposed to weight related health risks and that the proportion is more in Asian population with a high BMI. It was also suggested that the prevalence of diabetes in overweight and obese individuals are 2.9 times higher as compared to normal individuals [15]. This is clearly evident in our study where the proportion of individuals with high BMI were diabetic ( $\mathrm{p}$ value 0.0001). Obesity is a critical determinant of dyslipidemia. It operates through a number of metabolic influences like reduced insulin sensitivity and changes in fatty acid metabolism. Obesity is excess accumulation of fat which will impair the health. Dyslipidemia is an important risk factor for major heart diseases. The primary dyslipidemia in obesity is characterized by increased triglycerides, decreased HDL cholesterol and increased LDL cholesterol [16]. It correlates the association between body fat and atherogenic dyslipidemia. In our study, the most common pattern of dyslipidemia was combined 2 parameters, especially high LDL and low HDL which is largely consistent with the previous studies.

\section{Conclusion}

A basic principle of food and metabolism is that body weight change is associated with an imbalance between the energy content of food taken and energy expended by the body to maintain life and to perform physical activity.Such an energy balance framework is a powerful tool for investigating the regulation of body weight. However, we need a better understanding of the components of energy balance and their interactions over various time scales to explain the natural history of conditions such as obesity and to estimate the magnitude and potential success of therapeutic interventions [17].

Many meta-analysis has shown the association between the two disorders of obesity and diabetes. But then the correlation cannot be perfect, since not all obese individuals have type 2 DM and not all DM patients are obese. But a good proportion of obese individuals are diabetic. However, both of them share common features like insulin resistance and an atherogenic lipid profile [18]. Regardless of whether obesity responds to the body's insulin, the beneficial effect of weight loss is documented in diabetic patients. Therefore, according to the ASN, the American College for Sports Medicine, and the International Life Sciences Institute we have to form a panel committee which composed of members with expertise in energy metabolism, physical activity, weight management and behavior to review the published scientific literature and to hear presentations from other experts in these fields. Then only we can minimize and also postpone the complications of both obesity and diabetes mellitus.

\section{References}

[1]. WHO Technical Series Obesity: Preventing and managing the global epidemic. Report of a WHO consultation. World Health Organization Technical Report Series, 2000; 894: 1-253.

[2]. Guh, D.P., et al. The incidence of co-morbidities related to obesity and overweight:

[3]. A systematic review and meta-analysis. BMC Public Health, 2009; 9: 88.

[4]. Ramlo Halsted BA, Edelman SV. The natural history of type 2 Diabetes: Implications for clinical practice. Prim care, 1999; $26: 771-789$

[5]. Misra A, Khurana L. Obesity and the metabolic syndrome in developing countries. J Clin Endocrinol Metabolism 2008; 93(11 Supp11):S930.

[6]. Gupta R, Gupta VP, Sarna M, et al. Prevalence of coronary heart disease an risk factors in an urban Indian population: Jaipur Heart Watch2. Indian Heart J 2002;54(1):59-66.

[7]. Singh AK,Singh SK,Singh N.Obesity and dyslipidemia:Int J Biol Med Res 2011;2(3): 824-28.

[8]. Misra A., P. Chowbey, et al,. Consensus Statement for Diagnosis of Obesity, Abdominal Obesity and the Metabolic Syndrome for Asian Indians and Recommendations for Physical Activity, Medical and Surgical Management. JAPI, 57: 2009; 163-170.

[9]. Colditz, G.A., et al. Weight as a risk factor for clinical diabetes in women. American Journal of Epidemiology, 132, (1990);501-513.

[10]. Ni Mhurchu, C., et al. Body mass index and risk of diabetes mellitus in the Asia-Pacific region. Asia Pacific Journal of Clinical Nutrition, $15,(2006) ; 127-133$.

[11]. American Diabetes association. Standards of Medical care in Diabetes 2017. Diabetes care, 2017: 40 (1) S11 - S24

[12]. J. Tremblay, H. Morrissette, J.-M. Gagné, J. Bergeron, C. Gagné, and P. Couture, "Validation of the Friedewald formula for the determination of low-density lipoprotein cholesterol compared with $\beta$-quantification in a large population," Clinical Biochemistry, vol. 37, no. 9, 2004; pp. 785-790, View at Publisher · View at Google Scholar · View at Scopus

[13]. Grundy SM: Metabolic complications of obesity. Endocrine.13(2): 2000;155-165,

[14]. Laakso, M. (2010) Cardiovascular disease in type 2 dia- betes from population to man to mechanisms: The Kell West Award Lecture 2008. Diabetes Care, 33, 442-449.

[15]. Smita P, Sugumaran S, Bhate A, Mukherji A, Chandrakar S. Correlation of Blood Sugar with Waist Circumference and Body Mass Index in an Indian Population.

[16]. Global J. Pharmacol., 20126 (1): 08-11

[17]. Obesity. Preventing and managing the global epidemic, report of a WHO Consultation .WHO Technical Report Service 2000; 894:1 - 253.

[18]. Singh AK, SinghSK, Singh N, Agarwal N, Gopal K. obesity and dyslipidemia: Int J Biol Med Res, 2011, 2 (3): 824 - 828.

[19]. Kevin D. Hall,et al. Energy balance and its components: implications for body weight regulation,Am J Clin Nutr 2012;95:989-94. Printed in USA. 2012 American Society for Nutrition

[20]. Subhashini yaturu. Obesity and type 2 diabetes: Journal of diabetes mellitus 2011;1(4):79 - 95 . 